\title{
UN ESPEJO PARA LAS PERSONAS. DISRUPCIONES Y APORÍAS EN DOCUMENTOS CURRICULARES NACIONALES DE FINLANDIA
}

\section{Mirror for the People: Disruptions and Aporias in Finnish National Curriculum Documents}

\author{
Antti SAARI \\ Universidad de Tempera (Finlandia) \\ Correo-e: antti.saari@tuni.fi \\ Tuomas TERVASMÄKI \\ Universidad de Tempere (Finlandia) \\ Correo-e: tuomas.tervasmaki@tuni.fi
}

Recibido: I8 de octubre de 2020. Envío a informantes: 30 de octubre de 2020.

Aceptación definitiva: 6 de abril de 202I

REsumen: Los textos de los currículos nacionales son ejemplos de las dificultades inherentes a la representación y construcción de las nociones de ciudadanía en una sociedad democrática. Mientras que los soberanos predemocráticos recibían consejos maquiavélicos del tipo «espejos para príncipes», el currículum escolar moderno encarna una «lógica especular» del discurso político, proporcionando al pueblo una imagen de sí mismo como «unidad en la diferencia». Esta imagen se implementa y refuerza en el sistema educativo.

Utilizando la teoría política postfundacionalista, analizamos cómo se fabrican las representaciones de la ciudadanía en los discursos de los planes de estudio nacionales en una época de dislocación percibida, cuando la continuidad del orden político se ve amenazada. Como ejemplo de caso, utilizamos los discursos curriculares finlandeses -los currículos nacionales, así como los textos académicos para la planificación, la implementación y la evaluación de los currículos- desde la década de 1950 hasta la de 1970. Estos discursos construyen una tesis cultural de una nación en la que los antiguos símbolos de unidad nacional -basados en nociones románticas de país, lengua y fe- se están evaporando rápidamente. Se considera que los profundos cambios políticos, tecnológicos e industriales exigen una adaptación y una capacidad de cooperación más generales que antes, lo que equivale a una 
nueva orientación temporal o "choque de futuro», cuyo objetivo es responder a las exigencias futuras desconocidas en lugar de limitarse a asegurar un sentido de continuidad histórica.

Palabras Clave: currículum; historia de la educación; nacionalismo; Finlandia; teoría política.

AвSTRAст: National curriculum texts are prime examples of the difficulties inherent in representing and constructing notions of citizenship in a democratic society. Whereas pre-democratic sovereigns were given Machiavellian advice in the genre of 'mirrors for princes', the modern school curriculum embodies a 'specular logic' of political discourse, providing the people with an image of themselves as 'unity in difference'. This image is then implemented and reinforced in the education system.

Using post-foundationalist political theory, we analyze how representations of citizenship are fabricated in national curriculum discourses in an age of perceived dislocation - when continuity in the political order is seen threatened. As a case example, we use Finnish curriculum discourses - national curricula as well as academic texts for the planning, implementation and evaluation of curricula - from the I950s to the I970s. These discourses construct a cultural thesis of a nation where former symbols of national unity - based on romantic notions of country, language, and faith - are swiftly evaporating. Profound political, technological, and industrial changes were seen to require more general adaptation and cooperation skills than before, amounting to a new temporal orientation or 'future shock' - the aim of which was to respond to unknown future demands rather than to simply secure a sense of historical continuity.

KEY WORDS: curriculum; history of education; nationalism; Finland; political theory.

\section{Introducción: el currículum como un espejo para las personas}

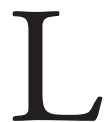

OS SISTEMAS ESCOLARES son esenciales para inculcar las nociones de unidad nacional en el Estado nación moderno. Los discursos curriculares nacionales implican estrategias de territorialización: trazan los límites alrededor de la comunidad nacional en cuestión y acentúan el conocimiento, las habilidades y los rasgos de personalidad que debería tener un ciudadano ideal de esa nación -no solo en el presente, sino también para el futuro (Fendler, 2006; Popkewitz, 2008; Camicia y Franklin, 20I0)-. El «ciudadano ideal» es una combinación de articulaciones socioculturales que incluye definiciones de identidad -tanto étnicas (basadas en el idioma, religión o raza) como cívicas (basadas en la relación 
de las personas con el Estado) - y definiciones de características y habilidades personales. Solo entonces, el ciudadano ideal puede convertirse en un objeto de identificación colectiva con el Estado y ayudar a mantener la cohesión social (Ahonen, 200I). Los contenidos de este ideal median entre el pasado y el futuro en la medida en que identifican y parecen reflejar diversas transformaciones sociales. Cuando se considera que las estructuras sociales se encuentran en estado de agitación, se realizan modificaciones sobre los viejos ideales para legitimar el sistema educativo bajo la luz de estos. En consecuencia, el ciudadano ideal es un concepto temporal y sus características solo pueden proporcionar bases parciales para la identificación. Esto refleja nuestra perspectiva posfundacional, que refuta la forma definitiva y unívoca de figuras metafísicas como la esencia, la universalidad y la totalidad en los imaginarios políticos (Marchart, 2007, pp. 2, I3-15). En cambio, estas características y categorías se perciben como contingentes, formadas discursivamente y mutables. Esta perspectiva desplaza la atención desde los «fundamentos existentes actuales» hacia sus condiciones de posibilidad y hacia sus procesos de construcción; en otras palabras: a cómo se construyeron en la forma de respuestas viables a problemas contemporáneos (Laclau, I994, pp. I-2; Marchart, 2007, pp. 13-15).

En este capítulo, abordamos los discursos curriculares entendiéndolos como imbuidos en sistemas de razonamiento históricamente construidos que gobiernan cómo se puede pensar y actuar sobre el alumno como un «ciudadano» y sobre la unidad en la diferencia de una sociedad (véase también Popkewitz, 2009). Vemos el texto del currículum nacional como un «espejo para las personas» que está imbuido en las aporías de la representación en el corazón de la democracia. Este término se refiere a un famoso género de la literatura política de la era europea de la soberanía, conocido como los «espejos para príncipes» y escrito sobre los objetivos, estrategias y técnicas de gobierno autocrático -el más conocido de los cuales fue El príncipe de Maquiavelo-. Con el advenimiento de la soberanía popular, sin embargo, el poder ya no emanaba de un autócrata, y tenía que ser representado de otra manera. Muchos teóricos políticos notables como Claude Lefort (1988) discuten sobre la soberanía de la gente en la era de la Ilustración, en términos del «lugar vacío» dejado por los gobernantes a raíz de las revoluciones políticas. El lugar vacío señala la necesidad de garantizar que la verdad, el poder y la ley no residan en un solo lugar, sino que están permanentemente dispersos y son negociables. Por lo tanto, la soberanía popular requiere un «conflicto institucionalizado» (Lefort, 1988: 17) entre diferentes ideales de gobierno democrático y las formas en que estos se implementan.

En términos políticos, la nación debe inventar imágenes de sí misma que reflejen unidad en la diferencia: objetivos e identidades comunes, al mismo tiempo que libertad individual y diferencias de opinión. Los currículos nacionales utilizan esas imágenes para fabricar las características de una nación, su ciudadanía

Para diferenciaciones conceptuales entre nacionalismo, ciudadanía e identidades políticas, véase, por ejemplo, MCCrone y Kiely (2000). 
y sus trayectorias pasadas y futuras. Aquí, el uso de «significantes vacíos» (por ejemplo, progreso, racionalidad, autonomía) -aparentemente- se vuelve esencial. Estos significantes se representan como convencionales y universales, pero también están «llenos» de contenidos muy particulares (Laclau, 2000, pp. 56-58). Centrarse en los significantes vacíos también resuena con el discurso que rodea al cosmopolitismo en la historia curricular (Popkewitz, 2008), donde la razón, la igualdad y la soberanía popular, es decir, los valores abstractos de la Ilustración, se implementan y reelaboran en el contexto de exigencias políticas y territoriales específicas.

Los discursos curriculares finlandeses de los años 50 a los 70 ofrecen un ejemplo sincero de tales tensiones. En este capítulo, nuestro conjunto de datos consta de dos currículos nacionales finlandeses, de 1952 y 1970, así como de textos académicos para la planificación, implementación y evaluación de estos currículos. Durante ese período, Finlandia solo había sido una democracia independiente durante unas pocas décadas y estaba experimentando un profundo «shock de futuro» en forma de industrialización, urbanización y un nuevo estado impreciso en la Guerra Fría. Estos desarrollos coincidieron con un rechazo simultáneo a los antiguos ideales pedagógicos del patriotismo, el lenguaje y Dios como símbolos de unidad. Estos fueron reemplazados por un énfasis más cosmopolita en la planificación racional y por los significantes de la ciudadanía social y psicológica.

\section{Futuros abiertos y significantes vacíos: aporías en la ciudadanía democrática}

La Ilustración estuvo marcada por dos desarrollos políticos amplios que coincidieron con aporías conceptuales distintivas. En primer lugar, se produjo una ruptura decisiva entre las formas pasadas y presentes de conceptualizar y actuar en el cuerpo social. El pasado dejó de ser la magistra vitae, de la que se debía extraer toda la sabiduría política, y el futuro quedó abierto a la planificación. Al mismo tiempo, aspectos dispares de la filosofía política y de las recientemente emergentes ciencias sociales comenzaron a confluir en torno a la cuestión de determinar las leyes inmanentes que gobiernan la sociedad. Los procesos y regularidades históricos eran ahora independientes de un ámbito trascendente, lo que permitía formar una aporía sobre si el futuro aún podía planificarse y gestionarse libremente con la continua expansión del capitalismo y la industrialización (Koselleck, 1988, 1997). El segundo desarrollo y fuente de aporía fue la universalización de los conceptos políticos. Muchos conceptos y categorías políticas, como la autonomía, la emancipación y la razón, asumieron una naturaleza cosmopolita y utópica en la Ilustración (Koselleck, 1997, pp. 22-23).

Los conceptos políticos se volvieron abstractos, expandidos, como eran, a toda la sociedad y, a veces, incluso a toda la humanidad. También eran utópicos en su pronóstico - presentaban principios normativos para ser realizados en el futuro (Koselleck, 1997)-. Ernesto Laclau identifica la naturaleza ambigua de estos «significantes vacíos», utópicos y abstractos, como poseedora de un peso o 
UN ESPEJO PARA LAS PERSONAS.

DISRUPCIONES Y APORÍAS EN DOCUMENTOS CURRICULARES NACIONALES DE FINLANDIA ANTTI SAARI Y TUOMAS TERVASMÄKI

relevancia especial sin tener un objeto específico de significación (Laclau, 2007, p. 36). Los actores políticos intentan definir su perspectiva de manera que alcancen popularidad y superen articulaciones rivales. Los conceptos o valores importantes del discurso, aquellos que se repiten o enfatizan de otras maneras, pueden ser llamados puntos nodales porque esos significantes unen interpretaciones divergentes, ocultan diferencias y aportan carácter al discurso (Howarth, 2000, p. IIO; Laclau, 2005, pp. I03-105). Los significantes más centrales de los discursos, como el «progreso", pueden funcionar como significantes vacíos ${ }^{2}$ y como representativos de una identidad común -universal, global y muy significativa-, aunque eventualmente se componen de contenidos ideológicos particulares (Laclau, 2000, pp. 56-58). La articulación de puntos nodales y significantes vacíos también dibuja los límites del discurso. Sin embargo, como el «progreso» es un significante vacío, su relación con un discurso o evento en particular nunca puede ser inamovible, y es por ello por lo que estos significantes permanecen sujetos a negociaciones y disputas constantes (Laclau, 2007, pp. 35, 57-60).

Los discursos curriculares son un ejemplo. La Ilustración, en sus diferentes espacios-tiempos geográficos y culturales, asistió al comienzo de los intentos pedagógicos de crear un «ciudadano mundial cuyos compromisos trascendieran las preocupaciones provinciales y locales con valores ideales sobre la humanidad» (Popkewitz, 2008, p. I). Los currículos nacionales empleaban ahora significantes vacíos como la razón, la igualdad y la democracia para fabricar la unidad en la diferencia. Luego se establecería una "cadena de equivalencia» (Laclau, 2007, pp. 56-57), vinculando significantes particulares, como los ideales, las asignaturas escolares y sus contenidos, con dichos objetivos. Llenar objetivos nobles y abstractos con contenidos particulares siempre implica excluir otros contenidos que, a su vez, pueden alimentar un debate crítico mayor. Por ejemplo, los currículos que operan en nombre de los ideales cosmopolitas de solidaridad, diversidad y ciudadanía mundial pueden ser criticados por ser demasiado eurocéntricos y negligentes con las culturas no occidentales (p. ej., Szkudlarek, 20I6).

En las siguientes secciones, comenzamos describiendo brevemente el contexto general de la sociedad finlandesa después de la Segunda Guerra Mundial. Luego pasamos a dar cuenta de las tres estrategias principales de los discursos curriculares finlandeses desde la década de 1950 hasta la de 1970. Las ideas de planificación racional, los discursos de lo social y los discursos psicológicos recién descubier-

Como tal, es evocador del «significante flotante» (signifiant flottant) de Claude Levi-Strauss, cuyo único significado es que es profundamente significativo, expresando algo importante que es común a todos. Claude LEFORT (1988, p. 232) también habla de una «representación flotante» que es importante en una sociedad democrática. El uso de LACLAU (2005) del significante flotante, sin embargo, difiere del de Lefort en que su significado es indeterminado. Por lo tanto, el significante flota precisamente porque hay una lucha continua, entre dos o más discursos, en torno a su significado particular (LACLAU, 2005, pp. I3I-I33). En resumen, cualquier significante puede pasar a ser «vaciado» $\mathrm{o}$ «flotante»: estos conceptos caracterizan el énfasis y la calidad que un significante particular recibe en el campo discursivo en un momento específico. 
UN ESPEJO PARA LAS PERSONAS.

IO8

DISRUPCIONES Y APORÍAS EN DOCUMENTOS CURRICULARES NACIONALES DE FINLANDIA ANTTI SAARI Y TUOMAS TERVASMÄKI

tos se desplegaron para proporcionar una base contemporánea de ciudadanía en tiempos cambiantes. En conclusión, resumimos nuestros hallazgos.

\section{Finlandia después de la Segunda Guerra Mundial}

Especialmente desde la Segunda Guerra Mundial, las democracias occidentales han enfatizado cada vez más la naturaleza caprichosa del cambio y de la complejidad social. En lugar de referirse únicamente a los símbolos de unidad y estabilidad, a menudo buscan reconocer la heterogeneidad y el cambio, manteniendo al mismo tiempo un sentido mínimo de objetivos compartidos y de continuidad (Laclau, 2007, p. 53). Finlandia ilustra este punto a su manera -presionada como estaba en su propio estado «reflexivo» al comienzo de la Guerra Fría-. Las representaciones de la ciudadanía finlandesa habían evolucionado con pausas y reanudaciones a partir de las primeras conmociones románticas nacionales de la identidad finlandesa en el siglo XIX, con discursos en la educación que iban reflejando estos cambios. Después de la independencia en 1917, Finlandia fue destrozada por una guerra civil. Para curar las cicatrices que quedaron después, se utilizó el sistema educativo para forjar un nuevo sentido de unidad nacional. Esto se basó en los ideales románticos alemanes del Estado nación, unificado por un idioma y una religión, y se manifestó en una obediencia luterana internalizada hacia el Estado (Rinne, 1984).

El período comprendido entre 1945 y principios de la década de los 80 -aproximadamente equivalente a la Guerra Fría- ha sido denominado la Segunda República en la política social y económica finlandesa (Alasuutari, 20I7). Durante esta era, siguiendo los pasos de Suecia, Finlandia se convirtió en un Estado de bienestar nórdico, con programas para proporcionar igualdad sanitaria, servicios sociales y educación básica para sus ciudadanos. El pináculo de esta era se produjo cuando, a finales de los años sesenta y principios de los setenta, el antiguo sistema dual finlandés de escuelas estatales fue reemplazado, después de mucho debate político y de muchos intentos fallidos, por una escuela común para todos (Ahonen, 2003).

La Segunda República también tuvo un papel claramente ambiguo en la política global. Después de perder la guerra con la Unión Soviética en 1944, Finlandia fue capaz de mantener lazos culturales, diplomáticos y económicos con Occidente solo al apaciguar a la URSS en las políticas externas e internas. Esta relación problemática también se reflejó en la autocensura de los medios de comunicación finlandeses y del debate político hasta la década de 1980 (Meinander, 2012) e, indirectamente, también en la politización de los debates educativos (Rantala, I997; Kärenlampi, I999).

Los discursos políticos finlandeses sobre la ciudadanía resuenan con distinciones entre continuidad y cambio, así como con los problemas de representación política ya expresados en los discursos políticos occidentales del siglo XIX. Al 
igual que en la política de Guerra Fría y en los esfuerzos de los EE. UU. por la cohesión social a través del sistema educativo (Cohen-Cole, 20I4), los discursos políticos finlandeses fueron reelaborados aún más en relación con las exigencias políticas percibidas en Finlandia en la era de la Guerra Fría. No obstante, los discursos finlandeses asumieron un carácter específico en los discursos nórdicos del siglo xx sobre un Estado de bienestar democrático y sobre la planificación racional. Al mismo tiempo, se introdujeron las estrategias de la planificación racional y los discursos de ciudadanía social y psicológica en los discursos curriculares.

\section{Planificación racional}

La primera estrategia para proporcionar unidad en la diferencia y continuidad en el cambio fue la planificación racional como un esquema general de preparación, implementación y evaluación del currículum. De hecho, como período, la Segunda República se caracteriza, a menudo, como presentando una creencia compartida en la posibilidad de una planificación racional y centralizada en diferentes áreas de la política, incluida la educación. La necesidad de una planificación racional surgió durante los años posteriores a la guerra, cuando Finlandia tuvo que aumentar su industrialización para pagar grandes reparaciones de guerra y reubicar al in \% de sus ciudadanos del territorio perdido a la URSS. Otro empuje se produjo en la década de I960, con una transición excepcionalmente rápida desde una economía en gran parte agraria a una industrial y de servicios, coincidiendo con la urbanización (Alasuutari, 20I7; Saari, 20I7). La planificación racional, la efectividad y la satisfacción de las «necesidades» de la sociedad (y especialmente de la industria) fueron términos que se filtraron en la planificación curricular y en la administración educativa tras la guerra -lo que refleja los desarrollos internacionales durante la Guerra Fría en la política educativa, por ejemplo, entre los países de la OCDE (Tröhler, 20I4)-.

Especialmente, la planificación del currículum de 1970 se representa a menudo como una adaptación de la Tyler rationale, ya que serializaba necesidades sociales, objetivos claramente definidos, métodos de instrucción y evaluación, en un ciclo de retroalimentación (Simola, 20I6). Sin embargo, la planificación racional centrada en el Estado en los procesos curriculares nacionales también conllevaba características únicas en respuesta a las exigencias políticas. En la atmósfera política altamente cargada que rodeaba a la reforma escolar en 1945, el Gobierno finlandés estableció un comité de administradores educativos y de políticos de la izquierda y de centro (principalmente de un entorno docente) para planificar un currículum nacional para las escuelas (kansakoulu). Su secretario era el profesor Matti Koskenniemi, el investigador educativo más famoso de la época (Hosio-Paloposki, 2006, pp. 9I-92). Kivinen (I988, pp. I82-I85) argumenta que, debido a la falta de recursos y a la necesidad de reubicar a muchos ciudadanos a lugares rurales, hubo presión política para subrayar la forma de vida agraria tradicional a 
pesar de la incipiente urbanización, mientras que al mismo tiempo había intentos por fabricar imágenes de democratización y modernización.

La planificación del currículum de 1952 fue supuestamente «democrática» y «abierta» en la medida en que reunió comentarios de investigadores, padres e instituciones culturales como la Iglesia. Los miembros del comité de planificación del currículum también escribieron extensamente, en libros y artículos de periódicos, sobre el proceso en marcha (Hosio-Paloposki, 2006, p. 93). En 1970, el comité de planificación del currículum combinó una planificación centralizada y racional y un diálogo abierto, ya que la reforma escolar comprehensiva en curso fue un asunto muy discutido entre los políticos y la sociedad en general. Aunque el comité de 1970 destacó la importancia de la representatividad, reconoció que no era «representativo de toda la sociedad» o de sus muchos intereses y formas de experiencia políticos, éticos y religiosos (Komiteamietintö, I970, pp. 2I, 74). Además, como se describía a la sociedad como hallándose en un estado de flujo perpetuo, se subrayó la necesidad de evaluar y revisar constantemente el currículum (p. 70). Para responder a estos desafíos, el comité y la Junta Nacional de Educación llevaron a cabo experimentos, encuestas y pruebas de rendimiento para representar y conciliar las múltiples voces dentro del sistema educativo (Saari, 20I2). Entonces, estos medios de recopilación de información fueron utilizados para proporcionar una infraestructura de retroalimentación constante para el sistema educativo, con la esperanza de que esta también proporcionaría los medios para responder a las demandas curriculares en el futuro y no solo en 1970 (Komiteamietintö, 1970, pp. 73-75).

Mientras que el currículum nacional de 1952 (Komiteamietintö, I952) aún mantiene imágenes de continuidad de una sociedad agraria, también declara que «la función del sistema escolar [estatal] es educar a los ciudadanos para una sociedad futura» (p. iı). Por lo tanto, la escuela y sus objetivos generales deberían estar «siempre actualizados» (pp. II-I4). Además, el currículum reconoce que la transformación social, no menos importante en términos de «cultura tecnológica» (p. II), plantea el desafío de educar a los ciudadanos para un futuro desconocido. Sin embargo, lo que es seguro, al menos, es que esta sociedad será una democrática (p. II). El currículum de I970 (Komiteamietintö, 1970) establece más claramente que, mientras que uno de los objetivos de la escolarización obligatoria era hacer al alumnado consciente de su patrimonio cultural y de su historia nacional, las escuelas también deberían esforzarse por transformarlo (p. 22). Aquí hubo un intento deliberado de delinear un futuro diferente correspondiente a la industrialización en curso, así como al cambio económico y tecnológico (p. I4). Esto indica que los planificadores del currículum habían identificado nuevas tendencias y trayectorias sociales que debían abordarse, pero no esperaban un acuerdo unánime sobre los medios (o fines) para hacerlo.

El currículum de 1970 establece que «la escolarización no puede planificarse solo de acuerdo con las necesidades sociales del momento presente. En cambio, debemos tener en cuenta el futuro, pero el desafío es que hay poca unanimidad en cuanto a por qué tipo de sociedad deberíamos luchar, o por cómo se verá en el 
año 2000, por ejemplo» (Komiteamietintö, 1970, p. 20). También hay un elemento de imprevisibilidad y referencias a la asombrosa velocidad de cambio -podría ser que el conocimiento y las habilidades que se enseñan hoy estén obsoletos en el futuro cercano (p. I4)-.

Aquí, parece que los currículos finlandeses de 1952 y 1970 se han encontrado con lo que Tomlinson (2007) ha denominado la «cultura de la velocidad»-un sinfín de preocupaciones originadas en la Europa industrializada de mediados del siglo XIX que combinaban el discurso del progreso tecnológico dinámico con la necesidad de separarse del pasado, conduciendo a una dificultad para lograr el equilibrio entre pronosticar el futuro y planificarlo, y entre ejecutar un cambio deliberado y adaptarse a los desarrollos inevitables-. Aun así, debe tenerse en cuenta que no hay nada natural o inevitable en estas representaciones del futuro. Los discursos sobre el futuro son en realidad una de las técnicas gubernamentales desarrolladas desde la Ilustración para prescribir formas de ciudadanía ideales y aparentemente inevitables en el presente (Hultqvist, 2006).

\section{Discursos de lo social}

Los discursos finlandeses de la filosofía política del siglo XIX acentuaron al Estado nación como un agente primario de cambio. Basándose principalmente en la filosofía hegeliana, J. V. Snellman (I806-I88I), estadista y profesor de pedagogía, vio que el Estado sigue un desarrollo racional en el curso de la historia, cuyos principios pueden discernirse a través de la especulación filosófica. Para el individuo, se alcanza una forma más elevada de libertad y racionalidad cuando vence sus deseos egoístas y toma el bien del Estado como el principio rector de sus acciones. Tal «acción republicana» requiere que el ciudadano sea educado sobre las leyes, la moral y las tradiciones culturales que gobiernan la nación (Snellman, I842/200I). Los discursos políticos hegelianos en Finlandia construyeron epistemologías positivistas y ontologías naturalistas como un otro que debería excluirse no solo porque se las consideraba epistemológicamente insostenibles, sino también porque se las consideraba una amenaza para la cosmología moral de la nación (Snellman, 1860/2004, p. 172).

Aunque la presencia del pensamiento hegeliano disminuyó en los discursos políticos y pedagógicos a finales del siglo XIX, todavía se podían encontrar rastros de él en los imaginarios comunitarios y nacionalistas de principios del siglo xx. Yrjö Ruutu (1920), un teórico político y posterior director de la Junta Nacional de Educación, afirmó que el avance de una nación sigue un desarrollo racional y orgánico, al que deben someterse las acciones e intereses de cualquiera de sus ciudadanos. Aceptar esta teoría, afirmó, era necesario no solo porque era verdad, sino también porque la nación finlandesa estaba profundamente dividida después de la guerra civil. Solo un «socialismo de Estado» autoritario y centralizado, sostiene Ruutu, mantendría la verdadera unidad orgánica de la nación (Ruutu, 1920). 
Siguiendo tendencias más amplias en las democracias occidentales de principios y mediados del siglo XX (véase Rose, 1999, p. 133), el «ciudadano social» se convirtió en una categoría importante en los discursos políticos sobre la democracia liberal en la Finlandia de la posguerra. Esto revirtió las relaciones entre el Estado y el ciudadano: el individuo ya no sucumbía a la racionalidad y la agencia del Estado. En cambio, el Estado ganaba su legitimidad y agencia a partir de los intereses y deseos de sus ciudadanos.

Un buen ejemplo del discurso de la ciudadanía y del Estado del bienestar durante la Segunda República es el libro de Política social en los años sesenta (6o-luvun sosiaalipolitiikka, 196I) de Pekka Kuusi, que fue anunciado como el «manual de modernización» en la década de 1960. El argumento sostiene que, como un Estado democrático moderno recientemente establecido, los ciudadanos de Finlandia se habían convertido en «la fuerza motriz detrás del poder estatal» y habían «asumido la más alta prioridad social en las acciones estatales» (Kuusi, I960, p. 3). Kuusi reconoce luego una tensión en que, aunque las políticas deben representar los intereses de los ciudadanos individuales, también deben hacerse para el bien de la humanidad en general, evitando así los intereses partidistas egoístas (Kuusi, I960, pp. 5-7). Esto refleja la «paradoja democrática» (Mouffe, 2000) más amplia de los discursos políticos occidentales: tratar de combinar los dos discursos inherentemente incompatibles de la autonomía individual y la igualdad universal.

Los fenómenos con el prefijo «social» ahora también se consideraban susceptibles a la investigación empírica en las ciencias sociales: se consideraba que la sociedad se mantenía unida, no a través de la racionalidad trascendente, sino de normas y regularidades inmanentes de interacción entre los individuos, que podían ser observadas. La sociología finlandesa se centró cada vez más en las nuevas «estructuras sociales» y en las «cuestiones sociales» de una sociedad en industrialización. Se publicaron importantes estudios sobre los criterios necesarios para la cohesión social en comunidades -para el aula (Koskenniemi, 1943), la unidad militar (Pipping, 1947) y los lugares de trabajo (Littunen, 1962)-. La terminología de tales estudios fluyó en discursos gubernamentales que discutían cómo las cuestiones sociales podrían manejarse mejor en el país para reflejar los intereses y el bienestar de sus ciudadanos.

En los discursos curriculares, la interacción social se entendía en referencia tanto a las observaciones realizadas en el aula como a los métodos de «educación social», que combinaban elementos de la Sozialpädagogik alemana con la educación democrática de Dewey (Saari, 2017). Desde la Sozialpädagogik, especialmente desde el famoso Plan Jena, estos discursos incorporaron las prácticas pedagógicas de los juegos, las festividades escolares y el trabajo en grupo, así como la noción de interacción social al servicio del patriotismo y del sacrificio para el conjunto (Koskenniemi, 1943). De los discursos curriculares finlandeses de Kilpatrick y los discursos de Dewey se tomó la noción de escuela como una sociedad embrionaria: la clase de la escuela tiene estructuras y vínculos sociales endógenos al igual que la sociedad circundante. Además, fomentar la interacción social supuestamente prepararía a los alumnos para una participación activa en 

ANTTI SAARI Y TUOMAS TERVASMÄKI

una sociedad democrática y dinámica (Koskenniemi, I968). Como Koskenniemi -el secretario del comité de planificación del currículum nacional de 1952- había traído a Finlandia muchos enfoques utilizados en primer lugar en la pedagogía social, el ciudadano social figuraba con fuerza en el texto del currículum. Como reflejo de las influencias alemanas, el currículum de 1952 seguía siendo prominentemente comunitario: se entendía al alumno a través de sus deberes y derechos hacia la comunidad escolar y el Estado nación. Sin embargo, estos lazos mutuos no eran vistos como impuestos desde arriba, sino como construidos sobre el funcionamiento orgánico de la comunidad:

Si a los niños se les permite participar activamente en la vida de la clase y se les asignan sus propias tareas, responsabilidades y amigos para trabajar en clase, entonces experimentan un sentido de pertenencia y se vinculan a la comunidad de la clase. En ese momento, las preguntas sobre la pulcritud o la atmósfera de la clase ya no son meros objetos de aprendizaje, sino asuntos por los que se esforzarán por resolver por sí mismos. (Komiteamietintö, 1952, p. 28)

Aunque el ideal de la interacción social alimentando al patriotismo, característico de los discursos de antes y durante la guerra, todavía era evidente en el currículum de 1952, también implicaba premoniciones de cambios sociales importantes dentro y fuera de las paredes del aula. Primero, las imágenes del ciudadano social coincidían con la transición percibida en los roles sociales y las jerarquías dentro del aula -los maestros ya no se consideraban como en absoluto control de la clase, sino como que deberían permitir una interacción y cooperación libres entre el alumnado (Komiteamietintö, I952)-. Así es como los discursos de la educación democrática y la pedagogía social trazaron los discursos políticos más amplios que representan una transición del poder soberano al popular (Saari, 20I7).

En segundo lugar, los discursos curriculares de lo social pretendían una disrupción importante en la sociedad finlandesa en la forma de una transición rápida a una sociedad industrial y una creciente heterogeneidad en los valores y creencias (Komiteamietintö, 1952). Como una «sociedad en miniatura», se pensaba que el aula podría ser el lugar donde se podrían enfrentar tales desafíos mediante el cultivo de habilidades sociales:

Cuando trabajan entre sus compañeros, los alumnos adquieren habilidades que luego usarán en las comunidades adultas: pueden tomar decisiones sobre problemas comunes y ajustar la rendición de cuentas por estos a través de la evaluación de las acciones de los demás desde perspectivas individuales y comunitarias. Una concepción de la moral se desarrollará efectivamente dentro de cada alumno durante la formación de su comunidad del aula. (Komiteamietintö, I952, p. 8I)

La sensación de disrupción social se vuelve más prominente en el currículum de I970: la necesidad de enseñar «habilidades sociales» está vinculada a los cambios generales en la sociedad en forma de urbanización, desarrollo tecnológico y alcance global de los problemas políticos (Komiteamietintö, 1970, p. I4). Aunque 
todavía hay descripciones amplias de las materias escolares en el currículum, sugiere que gran parte del contenido del currículum puede estar desactualizado para cuando el alumno ingrese al mercado laboral. El cambio tecnológico e industrial requiere que el alumnado aprenda las habilidades sociales necesarias para ser capaz de buscar y compartir información dentro de sus comunidades (p. I4); y para desarrollar valores y virtudes «favorables para la vida comunitaria», como la utilidad, la cordialidad y la moderación. Esto también podría ayudarles a encontrar soluciones a la «disonancia social» característica de la sociedad moderna (p. 47). Se esperaba que los nuevos «lazos sociales» así formados pudieran abordar cuestiones como la alienación, el abuso de sustancias y la violencia en las escuelas, que fueron consideradas como causadas por las recientes convulsiones estructurales en Finlandia (Saari, 2017).

En resumen, la idea de lo social es articulada como uno de los puntos nodales de los discursos curriculares. Aquí, lo social identifica y repara cambios profundos dentro y fuera del aula. Primero, hay un reconocimiento de que el maestro ya no es el soberano en el aula. Sin embargo, esto no conduce al desorden, sino a un orden social espontáneamente emergente en el aula. En segundo lugar, la sociedad está cambiando a un ritmo sin precedentes, lo que puede producir problemas sociales. Además, la velocidad del cambio implica un futuro imprevisible en cuanto a qué habilidades pueden ser necesarias. Estos desafíos pueden ser enfrentados a través de la interacción social en las escuelas.

Estos gestos dobles implican vacilaciones entre los diferentes significados de lo social. Por un lado, el concepto de lo social es un término estrictamente descriptivo: las estructuras sociales en forma de interacción entre el alumnado son empíricamente observables -siempre hay estructuras sociales en la escuela independientemente de qué y cómo se enseña en las escuelas-. Pero, de nuevo, los discursos de lo social también asumen un contenido normativo -hay demandas de que la escuela debe volverse más «social» en el sentido de dar espacio para la interacción entre el alumnado y evitar enfoques centrados en el maestro-. Entonces, lo social no es algo allí que pueda ser percibido, sino una sociedad por venir. Sin embargo, estos gestos dobles que afirman y niegan al mismo tiempo ciertas connotaciones de lo social no son un fracaso o una deficiencia en el uso de conceptos, sino un indicador de las múltiples funciones del término como un significante difuso.

\section{La emergencia de los discursos psicológicos}

Como señala Hannu Simola (2016), los discursos psicológicos que invisten al alumno con una interioridad mental conocible y controlable asumieron una posición prominente en los currículos nacionales finlandeses después de la Segunda Guerra Mundial. Este cambio fue de la mano con el debilitamiento de la imaginería nacionalista y cristiana y con el surgimiento de la investigación educativa empírica como base de la experiencia docente y de la planificación de políticas. 
UN ESPEJO PARA LAS PERSONAS.

DISRUPCIONES Y APORÍAS EN DOCUMENTOS CURRICULARES NACIONALES DE FINLANDIA

ANTTI SAARI Y TUOMAS TERVASMÄKI

Al igual que con los discursos de lo social, el carácter supuestamente positivista de los discursos psicológicos fue cuestionado en la pedagogía y la teoría política hegelianas del siglo XIX (Aho, 1993). El destacado político y pedagogo Eino-Sakari Yrjö-Koskinen (I858-I9I6) escribe en contra del estudio positivista del alma humana:

Es característico de la humanidad, en primer lugar, que el ser humano tiene un propósito más alto que un animal, y en segundo lugar, que en ningún lugar existe como un mero producto de la naturaleza, sino como un ser humano cultural que es diferente de acuerdo con diferentes tiempos y condiciones. Por lo tanto, un estudio de las leyes que dirigen el cuerpo y el alma no es suficiente. Es necesario tener conocimiento del propósito de la existencia humana según el cual debe ser educado. (Yrjö-Koskinen, I897, pp. I52-I53)

La psicología como un término que designa el estudio del alma quedó grabada en los discursos pedagógicos en el cambio de siglo. En lugar de alardear de los métodos experimentales y la ontología naturalista, unió el romanticismo nacional finlandés con el cristianismo y los principios epistemológicos del Geisteswissenschaften alemán (Saari, 20iI). Esto es evidente en el libro de psicología de Bruno Boxström para maestros y creadores de currículos, donde argumenta que los textos centrales de la cultura finlandesa-menciona la Kalevala épica nacional-son la puerta de entrada principal para comprender el «alma nacional». Las «partes más elevadas del alma humana», por otro lado, solo podrían entenderse mediante un estudio cuidadoso de la Biblia (Boxström, 1902).

A medida que las imaginerías nacionalistas y cristianas retrocedían, cada vez se extraían más influencias de la psicología educativa anglohablante para describir el sujeto, los objetivos y los procesos de la escolarización. En el currículum de 1952, se define la personalidad como un sitio de «experiencias educativas». Esto también incorpora un resultado ideal de educación en el que los valores comunales e individuales están bien equilibrados (Komiteamietintö, I952, p 26). Mientras que el currículum de 1952 terminó destacando la primacía de la cohesión grupal sobre la libertad y el desarrollo individual, el currículum de 1970 define el objetivo general de la educación como «ofrecer estímulos para el desarrollo de la personalidad única de cada alumno» (Komiteamietintö, 1970, p. 23, cursiva en el original). Más allá de eso, los currículos dicen muy poco sobre lo que esta personalidad realmente significa. En cambio, el concepto es un conector flexible para alojar una amplia variedad de trayectorias discursivas. Como tal, resuena con la «cultura de la personalidad» (Brinkmann, 20Io) en las sociedades democráticas. Por un lado, el significante refleja los ideales románticos del despliegue libre de la interioridad única propia de uno mismo y, por otro, las nociones científicas modernas del significante como un concepto psicológico y psiquiátrico desprovisto de connotaciones normativas (véase también Danziger, 1997). Por lo tanto, la personalidad tiene las características de un significante difuso en el sentido de que no significa estrictamente nada específico y aun así infunde respeto. Como 
tal, durante el siglo xx, la personalidad se convirtió en un foco para los discursos políticos psicologizados y «el sitio donde se sembraron y germinaron las semillas de los futuros problemas individuales y sociales» (Danziger, 1997, p. 127).

La personalidad como punto de encuentro de discursos dispares es discernible en la problemática de definir objetivos curriculares. Por un lado, el término personalidad se refiere a una idea holística que une las necesidades biológicas y los objetivos cognitivos, estéticos y religiosos (Komiteamietintö, I952, 1970). En su libro de texto sobre psicología educativa, Lehtovaara y Koskenniemi (1954) utilizan «desarrollar la personalidad» como un término paraguas para describir todos los objetivos educativos. Tener en cuenta la «personalidad completa» también era una forma de evitar hacer análisis psicológicos reductivos de los alumnos. Se insiste repetidamente en que, en diferentes situaciones de aprendizaje, los alumnos siempre reaccionarán con su "personalidad completa» y no solo con su inteligencia (Lehtovaara y Koskenniemi, 1954, pp. II9, 236, 281, 294). En un libro de texto didáctico de la década de 1970, que fue anunciado como el manual del maestro para implementar el currículum de 1970 (Simola, 1995), el desarrollo de la personalidad es indiscutiblemente el término paraguas que une todas las materias que se enseñan en la escuela (Lahdes, 1977, pp. 32-33; 4I-43). El autor se refiere al desarrollo de una «sociedad finlandesa tolerante» que permitirá «elecciones personales individualizadas» en lugar de simplemente homogeneidad (p. 36).

Por otro lado, los discursos psicológicos en las décadas de 1960 y 1970 acentuaron que los objetivos del currículum deberían definirse en términos estrictamente conductuales, no moralistas. Esto puede entenderse en el contexto de estrategias de planificación racional que destacan el cálculo preciso de medios y fines (Saari, 20I2). Hasta ahora, afirma Pentti Hakkarainen, los objetivos curriculares se han discutido como «problemas meramente filosóficos y éticos». Solo ahora están asumiendo un contenido «empírico» y «científico» (Hakkarainen, 1977, p. 37). A menudo, se reiteró que los objetivos operacionalizados del currículum deberían estar conectados con los diferentes aspectos de la «personalidad». Aquí la personalidad se refiere a la diferenciación en las taxonomías de Bloom entre los dominios cognitivo, afectivo y psicomotor, cada uno de los cuales contiene una taxonomía de objetivos conductuales precisos. Tener en cuenta estos dominios garantiza el «desarrollo sólido» de la «personalidad completa» (Lahdes, 1977, pp. $72-73,75)$.

El ejemplo de los fines y objetivos resalta la forma en que la personalidad, como un punto nodal y un significante difuso, podía servir a múltiples propósitos en los discursos curriculares. Podría albergar la idea del individuo sometido a una comunidad, así como de una entidad única con fuerte autonomía. Además, podría expresar un objetivo muy holístico de toda la educación, al mismo tiempo que estar conectada con las nociones conductistas de los objetivos operacionales.

Junto con la personalidad, el concepto de aprendizaje se convirtió en una categoría psicológica central en los textos curriculares de mediados del siglo Xx. En los libros de texto sobre didáctica y psicología educativa, se describe el aprendizaje como una función general de la vida, donde un organismo busca adaptarse a 

ANTTI SAARI Y TUOMAS TERVASMÄKI

su entorno. Atrás quedaron las problemáticas dicotomías entre el alma y el cuerpo. Aprender es vida y la vida no da saltos cuantitativos, sino que solo tiene grados de gradación (Bruhn, 1965; Lehtovaara y Koskenniemi, 1964; Heinonen, 197I).

Desde mediados de los años 6o, las teorías conductistas del aprendizaje de la tradición skinneriana se vuelven prominentes (Saari, 20II). Sin embargo, lo que es notable aquí no es el ascenso del conductismo per se, sino la forma en que se abordan los discursos conductistas del aprendizaje en relación con los cambios significativos identificados en la sociedad finlandesa. El profesor Veikko Heinonen (1971, pp. 16-17) escribe que el conocimiento del aprendizaje es de suma importancia para la educación en una era de cambios sociales y tecnocientíficos sin precedentes. Tal como lo ve, mientras que el «organismo humano» solía estar incrustado en un «campo de estímulos estático», ahora está en el fuego cruzado de flujos variables de información que exigen una adaptación incesante. Los humanos deben «aprender a aprender» constantemente (Heinonen, I97I, p. 23).

Aquí, el cambio se territorializa como una serie de estímulos y respuestas. Así es como también se domestica la precariedad de la sociedad tecnocientífica, ya que el alumno y su relación con el maestro y la clase escolar ahora se vuelven territorializados en el tiempo y el espacio como una relación entre estímulos y respuestas que se desenvuelven en la forma de un circuito de retroalimentación que puede ser medido y controlado (Heinonen, 1971). Aquí es donde cualquier futuro posible puede ser capturado. La garantía de control se ve apuntalada por la diferenciación entre psicología y cultura. Mientras que la cultura finlandesa está en constante cambio, el conocimiento psicológico es prácticamente atemporal, ya que, supuestamente, proporciona información que puede aplicarse en cualquier entorno social (Heinonen, I97I, pp. I4-15).

Destacar el aprendizaje llega al currículum nacional de 1970. El proceso primario de la educación escolar es el «aprendizaje», y el currículum se convierte en una descripción holística de las «experiencias de aprendizaje de los alumnos» y de las «situaciones de aprendizaje» (Komiteamietintö, 1970). Esto sucede en la medida en que la escuela como institución con normas disciplinarias y objetivos morales se vuelve ofuscada. Como señala Simola (2016), los discursos de aprendizaje describen qué educación habría «si la escuela no fuera una escuela».

\section{Conclusión}

En este capítulo, hemos ilustrado cómo los discursos curriculares construyeron narrativas de disrupciones en la sociedad en constante cambio, pero, al mismo tiempo, representaron una visión de un sistema educativo que sería capaz de cubrir estas dificultades y de crear cohesión social a través de la educación. Algunos de los argumentos presentados en estos currículos son representativos de las políticas educativas utilizadas en otros lugares del mundo occidental durante la Guerra Fría, pero nos hemos centrado en el caso finlandés, que se ha identificado a sí mismo con una rápida transformación social. Y si consideramos el 
UN ESPEJO PARA LAS PERSONAS.

desarrollo del discurso curricular finlandés, el cambio desde las ideas hegelianas de la cosmología comunitaria de mediados del siglo XIX, que Snellman promovió, hacia los discursos psicológicos empíricamente acentuados de la década de 1970 fue ciertamente radical, de un paradigma a otro.

Como espejos para las personas, los currículos finlandeses de 1952 y 1970 tuvieron que representar de formas novedosas a los ciudadanos de su democracia, que contaba con unas pocas décadas de existencia. Una noción central era que el currículum debería responder a desarrollos futuros desconocidos mediante el cultivo de la adaptabilidad general entre los ciudadanos, en lugar de centrarse simplemente en ciertos sujetos. Los currículos movilizaron nociones de planificación racional y centralizada, pero los discursos de lo social y el significante vacío de «personalidad» fueron capaces de admitir una amplia gama de heterogeneidad y la existencia de una pluralidad democrática. En lugar de utilizar un discurso autoritario, el currículum forjó significantes difusos de unidad a partir de una plétora de voces e intereses, y significantes de continuidad durante un período de cambio acelerado. Como tal, ilustran las aporías inherentes al pensamiento político desde la Ilustración y proporcionan un catalizador crucial para cualquier discurso que describa, desafíe o legitime el poder político en las sociedades democráticas.

\section{Bibliografía}

Aно, J.: Sieluun piirretty viiva (A Line Drawn in the Soul), Oulu, Pohjoinen, 1993.

Ahonen, S.: «Politics of identity through history curriculum: narrative of the past for social exclusion - or inclusion?», Journal of Curriculum Studies, 33(2) (200I), pp. I79-194.

Ahonen, S.: Yhteinen koulu - tasa-arvoa vai tasapäisyyttä? (Common School: Equality or Dullness?), Tampere, Vastapaino, 2003.

AlasuUtari, P.: Tasavalta: Sodan jälkeisen Suomen kaudet ja trendit (The Republic: Post-War Eras and Trends), Tampere, Vastapaino, 2017.

Boxströм, B.: Kasvatusopillinen sieluoppi (Educational Psychology), Sortavala, Karjalan kirjakauppa- ja kustannusliike, I902.

BRINKMANN, S.: «Character, personality, and identity: On historical aspects of human subjectivity», Nordic Psychology, 62 (2010), pp. 65-85.

Bruhn, K.: Johdatus opetusoppiin (Introduction to Didactics), Porvoo, WSOY, 1965.

Camicia, S. P. y Franklin, B. M.: «Curriculum reform in a globalised world: The discourses of cosmopolitanism and community», London Review of Education, 8(2) (2010), pp. 93-I04.

Cohen-Cole, J.: The Open Mind. Cold War Politics and the Sciences of Human Nature, Chicago, The University of Chicago Press, 2014.

DANZIGER, K.: Naming the mind. How psychology found its language, London, Sage, 1997.

FendLER, L.: «Educating flexible souls: The construction of subjectivity through developmentality and interaction», en Hultqvist, K. y Dahlberg, G. (eds.): Governing the child in the new millennium, New York: RoutledgeFalmer, 200I, pp. II9-I42.

Hakkarainen, P.: Peruskoulun tavoitetutkimus V (Study of Comprehensive School Aims, vol. 5), Jyväskylän yliopisto, Kasvatustieteiden tutkimuslaitos, 1977.

Heinonen, V.: Oppimisen psykologia opetustyössä (Psychology of Learning and Teaching), Jyväskylä, Keskisuomalainen, I97I. 
UN ESPEJO PARA LAS PERSONAS.

DISRUPCIONES Y APORÍAS EN DOCUMENTOS CURRICULARES NACIONALES DE FINLANDIA

ANTTI SAARI Y TUOMAS TERVASMÄKI

Hosio-Paloposki, A.: Koulukasvatusta teknologisoituvaan yhteiskuntaan: kansakoulun opetussuunnitelman rakentuminen, I945-I952 (School Education for a Technologizing Society: Construction of the Elementary School Curriculum, 1945-1952), Helsinki, Historiallis-yhteiskuntatiedollisen kasvatuksen tutkimus- ja kehittämiskeskus, 2006.

Hovi, R.: Kivinen, O. y Rinne, R.: Komitealaitos, koulutusmietinnöt ja koulutuspolitiikan oikeutus: Ammatillisen ja akateemisen koulutuksen oikeutusperustelujen muutokset suomalaisissa koulutusmietinnöissä 1860-luvulta 1980-luvun lopulle (Committee Institution, Education Reports and the Legitimation of Education Policy: Changes in Justification in Finnish Education Reports I860s-I980s), Turku, Turun yliopisto, I989.

Howarth, D.: Discourse, Buckingham, Open University Press, 2000.

Hultqvist, K.: «The future is already here - as it always has been: The new teacher subject, the pupil, and the technologies of the soul», en Popkewitz, T. S.; Petersson, K.; Olsson, U. y KowalcZYK, J. (eds.): «The future is not what is appears to be»: Pedagogy, genealogy and political epistemo$\log y$, Stockholm, HLS Förlag, 2006, pp. 20-6I.

Kansanen, P.: «Ovatko Peruskoulun opetussuunnitelmakomitean esittämät tavoitteet käyttäytymistavoitteita?» («Are the Aims Presented by the Comprehensive School Committee Behavioral Aims?)», Kasvatus, 2(2) (1971), pp. 86-92.

KärenlamPI, P.: Taistelu kouludemokratiasta: Kouludemokratian aalto suomessa (Battle for School Democracy: The Wave of School Democracy in Finland), Helsinki, SHS, 1999.

KIvinen, O.: Koulutuksen järjestelmäkehitys: Peruskoulutus ja valtiollinen kouludoktriini Suomessa I800- ja I900-luvuilla (Education System Development: Comprehensive Schooling and the National School Doctrine in the $19^{\text {th }}$ and $20^{\text {th }}$ Centuries), Turku, Kirjapaino Pika Oy, 1988.

КомітеАмietintö: Kansakoulun opetussuunnitelmakomitean mietintö 2. Varsinaisen kansakoulun opetussuunnitelma (Elementary Curriculum Committee Report: Elementary School Curriculum), Helsinki, Valtioneuvoston kirjapaino, 1952, p. 3.??

Komiteamietintö: Peruskoulun opetussuunnitelmakomitean mietintö I. Opetussuunnitelman perusteet (Comprehensive School Curriculum Committee Report: Comprehensive School Curriculum), Helsinki, Valtion painatuskeskus, I970, p. A 4.??

Koselleck, R.: Critique and crisis. Enlightenment and the pathogenesis of modern Society, Cambridge, MIT Press, I988.

Koselleck, R.: «The Temporalization of Concepts», en Finnish Yearbook of Political Thought 1997, vol. I, Publications of Social and Political Sciences and Philosophy (SoPhi), Io, Jyväskylä, 1997, pp. 6-24.

Koskenniemi, M.: Koululuokan pienoisyhteiskunta (The School Class as a Miniature Society), Helsinki, Otava, 1943.

Koskenniemi, M.: Sosiaalinen kasvatus koulussa (Social Education in the Schools), Helsinki, Otava, I968.

KuUsi, P.: 6o-luvun sosiaalipolitiikka (Social Politics for the 1960s), Helsinki, WSOY, I96I.

LAClaU, E.: «Introduction», en LAClaU, E. (ed.): The making of political identities, London, Verso, I994, pp. I-IO.

LACLAU, E.: «Identity and hegemony: The role of universality in the constitution of political logics», en Butler, J.; Laclau, E. y Zizek, S. (eds.): Contingency, hegemony, universality. Contemporary dialogues on the left, London, Verso, 2000, pp. 44-89.

LaClau, E.: On populist reason, London, Verso, 2005.

LACLAU, E.: Emancipation(s), London, Verso, 2007.

Lahdes, E.: Peruskoulun uusi opetusoppi (New Didactics for the Comprehensive School), Helsinki, Otava, 1977.

Lefort, C.: Democracy and political theory, Cambridge, Polity Press, I988.

Lehtovana, A. y Koskenniemi, M.: Kasvatuspsykologia (Educational Psychology), Helsinki, Otava, I954. Littunen, Y.: Sosiaalinen sidonnaisuus (The Social Bond), Porvoo, WSOY, 1962. 
UN ESPEJO PARA LAS PERSONAS.

Marchart, O.: Post-foundational political thought. Political difference in Nancy, Lefort, Badiou and Laclau, Edinburgh, University Press, 2007.

McCrone, D. y Kiely, R.: «Nationalism and citizenship», Sociology, 34(I) (2000), pp. 19-34.

Meinander, H.: Tasavallan tiellä: Suomi kansalaissodasta 200o-luvulle (On the Path Towards the Republic: Finland from the Civil War to the 200os), Helsinki, Schildts \& Söderströms, 2012.

Miller, P. y Rose, N.: Governing the present: Administering economic, social and personal life, Cambridge, Polity Press, 2008.

Mouffe, C.: The democratic paradox, London, Verso, 2000.

PIPPING, K.: Kompaniet som samhälle: Iakttagelser $i$ ett finskt frontförband I94I-I944 (The Platoon as a Society: Observations on a Frontline Platoon I94I-I944), Turku, Åbo Akademi, 1947.

Popkewitz, T. S.: «The production of reason and power: Curriculum history and intellectual traditions», Journal of Curriculum Studies, 29(2) (1997), pp. I3I-I64.

Popkewitz, T. S.: Cosmopolitanism and the age of school reform: Science, education, and making society by making the child, New York, Routledge, 2008.

Popkewitz, T. S.: «Curriculum study, curriculum history, and curriculum theory: the reason of reason», Journal of Curriculum studies, 4I(3) (2009), pp. 301-319.

Rantala, J.: Sopimaton lasten kasvattajaksi: Opettajiin kohdistuneet poliittiset puhdistuspyrkimykset suomessa 1944-1948 (Unsuitable for Educating Children: Political Purges of Teachers 1944-1948), Helsinki, SKS, 1997.

RiNNe, R.: Suomen oppivelvollisuuskoulun opetussuunnitelman muutokset vuosina 1916-1970: opetussuunnitelman intentioiden ja lähtökohtien teoreettis-historiallinen tarkastelu (Changes in the Curricula of Finnish Obligatory School Curricula 1916-1970. A Theoretico-Historical Analysis of Curricular Ideals), Turun yliopiston julkaisuja. Sarja C, Scripta lingua Fennica edita, osa 44, Turun yliopisto, 1984 .

Rose, N.: Powers of freedom: Reframing political thought, Cambridge, Cambridge University Press, 1999.

RuUtu, Y.: Uusi suunta, 1920.

SAARI, A.: Kasvatustieteen tiedontahto: Kriittisen historian näkökulmia suomalaiseen kasvatuksen tutkimukseen (Educational Research and Will to Knowledge: Critical History of Finnish Study of Education), Jyväskylä, FERA, 20II.

SAARI, A.: «The Map is the Territory: educational evaluation and the topology of power», European Educational Research Journal, II(4) (2012), pp. 586-600.

SAARI, A.: «Technique of Freedom: Representing the School Class as a Social Order», en PopkewITZ, T.; Diaz, J. y Kirchgasler, K. (eds.): A Political Sociology of Educational Knowledge, New York, Taylor \& Francis, 20I7, pp. 2II-225.

SARJAla, J.: Suomalainen koulutuspolitiikka (Finnish Education Policy), Juva, WSOY, 1982.

Simola, H.: The Finnish education mystery: Historical and sociological essays on schooling in Finland, New York, Routledge, 2016.

Snellman, J. V.: «Valtio-oppi (Political Theory)», en Kootut teokset 5, Helsinki, Opetusministeriö, I842/200I, pp. 32-293.

SNellman, J. V.: «Ihmiskunnan uudistamisesta lastentarhojen välityksellä. (Reforming Mankind Through Kindergartens)», en Kootut teokset I7, Helsinki, Opetusministeriö, I860/2004, pp. 165178 .

SzKudlareK, T.: «Laclau's ontological rhetoric, universality and collective identity: A lesson for cosmopolitan education», en Papastephanou, M. (ed.): Cosmopolitanism: educational, philosophical and historical perspectives, Berlin, Springer, 20I6, pp. 20I-2I4.

Tomlinson, J.: The culture of speed: The coming of immediacy, London, Sage, 2007.

YRJÖ-Koskinen, E-S.: «Tieteellisestä kasvatusopista. (On Scientific Education)», Kasvatusopillinen aikakauskirja, 34 (I897), pp. I5I-I57.

(Traducción de Domingo Barroso, Universidad de Granada) 